\title{
Numerical analysis of the surface and geometry of plate fin heat exchangers for increasing heat transfer rate
}

\author{
Iman Shahdad ${ }^{1} \cdot$ Farivar Fazelpour ${ }^{2}$
}

Received: 20 January 2018 / Accepted: 12 March 2018 / Published online: 19 March 2018

(c) The Author(s) 2018

\begin{abstract}
This paper investigates the flow field and turbulent flow heat transfer around an array of plain and perforated fin using Fluent software within the range of 20,000-50,000 Reynolds. Regarding the turbulent flow, the $k-\varepsilon$ RNG turbulence model was implemented, and SIMPLE algorithm was used for solving the equations of three-dimensional, steady, and incompressible flow. In the simulation process, air was considered as the working fluid with consistent physical properties. The results revealed that perforated fins increase the heat transfer coefficient as well as Nusselt number. The highest heat transfer coefficient and Nusselt number was achieved for perforated fins with two square holes. Moreover, it was concluded that increase of Reynolds number notably increases the heat transfer coefficient and Nusselt number. The total drag force imposed to plain fins was higher than the force imposed to perforated fins. As a result, by changing plain fins into perforated fins, the pressure decreases due to passage of the flow through the pins, and accordingly, the total drag force imposed to the fins decreases. Finally, it was revealed that attaching some pins on the plain fins along the passing flow will decrease the pressure, while notably increase the heat transfer. Furthermore, it can reduce the fins' weight and price.
\end{abstract}

Keywords Convection heat transfer $\cdot$ Reynolds number $\cdot$ Nusselt number $\cdot$ Total drag force $\cdot$ Turbulent flow

\section{Introduction}

Since 1973 oil crisis (when the members of the Organization of Arab Petroleum Exporting Countries announced an oil sanction), environmental issues including energy saving has increasingly found importance. Moreover, world population growth has led to increase of energy demand. Although energy consumption has brought about great profits, such issues as environmental pollution and the effects of consuming energy resources over human health has caused a number of concerns to emerge. One of the keys to resolve this problem is "Meaningful Energy Conservation", and a precondition of realizing this concept is design and definition of operational conditions for heat exchangers.

Farivar Fazelpour

f_fazelpour@azad.ac.ir

1 Department of Mechanical Engineering, Faculty of Engineering, Islamic Azad University, South Tehran Branch, Tehran, Iran

2 Department of Energy Systems Engineering, Faculty of Engineering, Islamic Azad University, South Tehran Branch, Tehran, Iran
A heat exchanger is a machine that transfers the heat of a fluid to one or more other fluids with different temperatures. As a result, the heat exchangers are implemented in all industrial and commercial usages, and even those aspects of normal life that are related to energy transfer. Each living creature is somehow equipped with a heat exchanger. Heat exchangers are manufactured in very small and very huge sizes. The smallest heat exchangers (less than $1 \mathrm{~W}$ ) are used for superconductor electronic applications, guiding missiles controlled by the thermal source, etc. The biggest heat exchangers (more than $1000 \mathrm{~mW}$ ) are implemented in large power plants as boiler, condenser or cooling tower. Heat exchangers are widely used in different industrial units like power plants, refineries, metal molding and glass industries, food and medicine industries, paper making, petro chemistry, cold storage, heating and cooling systems for buildings, gas congestion industries, land, sea and space vehicles, and finally electronic industries.

Smaller size of a heat exchanger is a measurement of industrial growth at present [1]. Regarding the increasing growth of cryogenics, plate fin heat exchangers are usually appropriate for implementation in a wide range of industries. The plate fin units are usually used in counter flow 
heat exchangers. This type of heat exchangers have thin corrugated fins or corrugated heat transfer surface of the plates [2]. The density of small heat exchangers' surface is very high, and it can be as much as $1800 \frac{\mathrm{m}^{2}}{\mathrm{~m}^{\mathrm{m}}}$. Due to its high heat transfer rate, plate fin heat exchangers are highly important now, and are widely used [3].

Regarding the energy transfer, efficiency of heat exchangers in satisfaction of the requirements for energy standards (based on low cost and environmental impact) is highly important [4]. In this paper, first, the plate fin heat exchangers and their performance has been considered, and then a plate fin heat exchanger in Ansys-Fluent was simulated to analyze the geometry of different fins, heat transfer, and pressure drop in different Reynolds numbers. Finally, the simulation results will be compared with each other to obtain the highest rate of heat transfer among Reynolds numbers.

There are well-cited researches in this regard. Johnson and Moshfegh made an experiment on seven different types of thermal performance of plate fin, strip fin, and pin fin heat sinks in a wind tunnel with turbulent flow. The authors investigated thermal resistance and pressure drop [5]. Kays and London conducted a number of integrated experiments to obtain such factors as friction and heat transfer for different types of plate fin heat exchangers [6]. Velayati and Yaghoubi conducted a numerical study on an array of parallel fins, and calculated the Nusselt number and pressure drop in the turbulent flow by changing the width of the fins and the distance among them. By decreasing the proportion of fins' width to the distance among them, the Nusselt number and friction coefficient increased both [7]. Razelos and Kakatsios obtained the optimal dimensions of the fins with Heat transfer and radiation heat transfer. The authors investigated hyperbolic fins and achieved the results by simplifying the equations [8].

Computational fluid dynamics has a good flexibility in formation of computational models, in a way that required physical conditions will be prepared for the model, without any need to construct an experimental model. Wang, et al. conducted a numerical study on fluid flow and heat transfer in plain and offset plate fin heat exchangers within the quiet Reynolds number range. The researchers compared the results of their study with the results of Kays and London [6] at the end [9]. Asako and Faghri analyzed the heat transfer characteristics in a turbulent flow around arrays of heated blocks encountered on the wall of two parallel sheets on a channel. A wide range of geometrical parameters were considered in this study, and $k-\varepsilon$ turbulence model was implemented to solve the equations [10]. Flow behavior in plate fin heat exchangers has been analytically and experimentally analyzed due to the complexities of this subject [11-17]. Moreover, Mueller and Chiou studied different types of flow distribution in heat exchangers [18].
Wais analyzed the influence of fin thickness and winglet orientation on mass and thermal efficiency of cross-flow heat exchanger. In this study, the fin thickness, length, and orientation of winglet were the major parameters under analysis. Numerical analyses were undertaken to analyze the finned tube heat exchanger with and without winglets at the fin surface. It was concluded that fin thickness is influential over the mass of whole heat exchanger as well as the manufacturing costs, while proper orientation of the winglet can improve the heat transfer. The correlation between the heat exchanger's weight and heat transfer was also investigated in this research for different fin configurations. 3D models were utilized for obtaining the properties of heat transfer between finned tube and the air. The results of this study revealed that optimization cannot be undertaken for merely one criterion, and more than one parameter should be considered to improve the heat exchanger's efficiency. All the calculations in this study revealed that the ratio of heat exchanger's mass to heat transfer is an essential parameter to which careful attentions must be paid in the process of the heat exchanger design [19].

Han et al. undertook a numerical analysis of the fluid flow and heat transfer characteristics in finned tube heat exchangers through analysis of different oval and circular tubes. Three different models of tube with two types of enhanced fins (wavy and louvered fins) were used. The results of this study showed that usage of oval fin-tube is not only able to reduce flow resistance, but also able to improve the heat transfer capacity of the heat exchangers. This issue can improve the efficiency of the fin's performance too. Regarding the heat transfer rate for the louvered fins, it was revealed that heat transfer coefficient is more important than the heat transfer area [20].

Čarija et al. in their study investigated the fluid flow and heat transfer in a fin and tube heat exchanger. A comparison between the characteristics of fin and tube heat exchanger and flat and louvered fins exchangers within the range of 70-350 of Reynolds number. The results of the study reflected that louvered heat exchangers show better heat transfer characteristics and lower pressure drop. Computational fluid dynamics was validated through comparing the results of numerical simulation and the experimental results. The output of the research reflected minimum average of Nusselt number deviation, and almost complete corresponding pressure drop [21].

Yeom et al. studied the heat transfer and pressure drop characteristics of micro pin fin arrays in a narrow rectangular channel with an air through flow. In this study, the flow rate moved from laminar flow toward turbulent flow. Copper micro pin fins with $150-400 \mu \mathrm{m}$ length and $75-700 \mu \mathrm{m}$ diameter were made. Furthermore, the performance proportions that calculate the heat transfer characteristics with respect to the pressure drop were employed to study the 
performance of micro pin fins surface. The results of this study revealed that role of the fluid dynamic effects generated around micro pin fins is more important than the area increase due to micro pin fins in improvement of heat transfer. The maximum amount of heat transfer improvement for plain surface was equal to $79 \%$ that due to the micro pin-fin surface with $250 \mu \mathrm{m}$ height and $400 \mu \mathrm{m}$ diameter [22, 23].

Manufacturing heat wells has widely been studied, and so far, a number of methods are presented for improving this procedure. However, there is not much study conducted on perforated fins in turbulent flow fluid. According to the results of the previous research, the best performance of external fins is achieved through the use of hyperbolicshaped fins. However, due to difficulty of manufacturing as well as manufacturing high costs of hyperbolic fins, simple rectangular fins are used in industry. As a result, it can be mentioned that novelty of the present research is in analyzing the perforated fins in turbulent flow.

\section{Concept}

Heat exchangers are equipment that enables heat flow among two or more fluids with different temperatures. Heat transfer in a heat exchanger usually occurs as heat exchange in each fluid, and thermal conductivity through separating wall.

\section{Types of heat exchangers}

Heat exchangers are made according to different measures like transfer procedure, structural geometry and component arrangement [24]. Different types of heat exchangers will be mentioned in this section.

- Compact heat exchangers in which the heat exchange rate per unit volume is high (higher than 700). This type of heat exchangers includes a compact set of tubes or finned flat surfaces [24]. Plate fin heat exchangers are a type of compact heat exchangers that are composed of a number of parallel plates (which are usually known as separating plates), as shown in Fig. 1. The plates are attached to

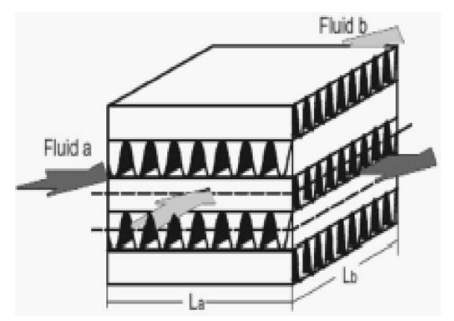

Fig. 1 A schematic view of plate fin heat exchanger for turbulent flow [25] each other by means of some fins with different shapes and geometries. These finned paths are in fact the path from which the flow passes in the heat exchanger. Thicker plates are selected for blocking the sideways of the flow passage path. Offset strip fins are among the most commonly used fins in these heat exchangers. A schematic view of this type of fin is depicted in Fig. 2. This type of fin has high heat transfer efficiency, acceptable compaction, and high reliability. That is why offset strip fins are widely used in cooling systems of airplanes, automobiles, and other industrial cooling systems. Offset strip fins are more efficient than pin fins regarding the heat transfer. Moreover, the offset strips are better than perforated fins regarding the strength and reliability [25].

- Shell-tube heat exchanger which is considered as a type of tube heat exchangers. This heat exchanger is one of the most common equipment of heat transfer in industry [26]. Almost $85 \%$ of the heat exchangers used in refineries, petro chemistries, and power plants are shell-tube heat exchangers [27]. Although this heat exchanger is not necessarily compact, its high capacity and structural formation has made it suitable for most of the industrial applications [26].

- Air cooler is a heat exchanger with tube equipment for heat transfer. The tubes are exposed to air, and the passing air works as a cooler of the fluid inside the tubes [26].

- Double pipe heat exchanger which is made up of a straight pipe or a finned pipe that is placed into another pipe with higher diameter. In some types of this heat exchanger, a group of pipes are placed into larger pipes. This heat exchanger is specifically appropriate for low capacity, interoperability and high pressure cases [26].

- Heat pipe heat exchangers which consists of an envelope, working fluid, and in most cases, a wick that must form a consistent and strong bond with the surface of internal case [26].

- Plate heat exchangers which are made of thin metal plates attached to each other closely with a distance of 3-6 $\mathrm{mm}$. The heat exchanger fluid flows through the plates interchangeably [24].

- Different types of plate heat exchanger: Plate-and-frame heat exchangers, gasketed plate heat exchangers, spiral

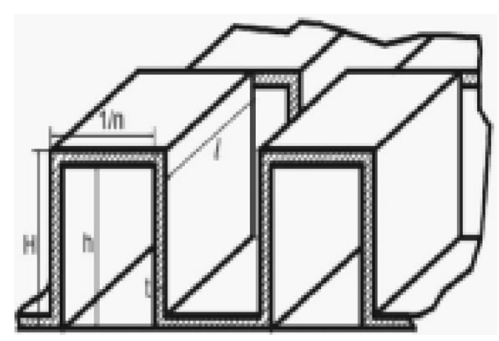

Fig. 2 An offset strip fin [25] 
plate heat exchangers, lamella heat exchangers, panel coil heat exchangers [24].

\section{Different types of fin}

Corrugated plates that are placed between the flat plates to increase the heat transfer surface, and provide a mainstay for the flat plates too. There are different types of corrugated plates used in heat exchangers; however, the most commonly used types are plain fin, perforated fin, serrated fin, and herringbone fin. By use of the fins, the boundary layers will break and disrupt completely. If the surface is wavy along the flow direction, boundary layers become thin or break; and, the result will be higher heat transfer coefficient and higher pressure drop [24].

Fast heat transfer from hot surface, reduction of pressure drop, reduction of weight and cost of the heat exchanger are the goals of designers. Extended surfaces are good equipment for heat transfer between fluid and environment, and are extensively used in industries. Rectangular plain fins are used in industries for cooling hot surfaces.

\section{Methodology}

In this paper, first the plate fin heat exchangers and their performance is studied. After data collection, a plate fin heat exchanger will be modeled through a CFD commercial code (Ansys Fluent); geometry of different fins, heat transfer, and pressure drop in different Reynolds numbers will be estimated; and finally, the obtained results will be compared and analyzed to find the highest rate of heat transfer for Reynolds numbers. A great number of meshing are considered for evaluation of the simulation method, and the result will be selection of a meshing with appropriate dimension. Simulation will be done after selection of the meshing with suitable number and dimension. In this regard, the flow equations are solved in a 3D manner, and the equations of heat transfer around an array of fins will be solved by numerical method. The governing equations are solved through finite volume method, by use of SIMPLE algorithm, and by applying $k-\varepsilon$ turbulence model. After obtaining simulation results, they will be compared with the experimental results to provide a validated model with a particular error percentage. The provided model can be used later for analysis and modeling of other problems.

\section{Preprocessing}

Preprocessing is a phase in which the aims of modeling (like geometry creation) and meshing creation are done. The next phase will be definition of numerical models and boundary conditions for beginning equation solution. The solver will go on till a complete convergence is achieved in the solution. When the solver is done, the results will be analyzed numerically and graphically. The former phase is called post-processing.

Figure $3 \mathrm{a}$ depicts the components of the computational domain for a plain rectangular fin. Figures $3 b$ and $3 c$, respectively, depict a rectangular fin with two square holes, and a rectangular fin with one rectangular hole.

Computational domain is a rectangular cube with $86 \mathrm{~mm}$ of length, $46 \mathrm{~mm}$ of width, and $31 \mathrm{~mm}$ of height. The fin material is aluminum, and their dimension is $24 \mathrm{~mm}$ for length, $4 \mathrm{~mm}$ for width, and $12 \mathrm{~mm}$ for height. The distance between the fins is $10 \mathrm{~mm}$. The dimension of holes in the fin with two square holes is $3 \times 3 \mathrm{~mm}$, and the dimension of the hole in the fin with one rectangular hole is $2 \times 9 \mathrm{~mm}$.

The second section of preprocessing is creation of computational cells. Definition of computational cells or meshing is an important phase in an accurate numerical solution. The meshing section of the ANSYS software is equipped with different algorithms for meshing. In this paper, a triangle grid was considered for rectangular cube area and for the fins. Figure 4 displays a general view of the meshing, and Fig. 5 displays a close view of the meshing.
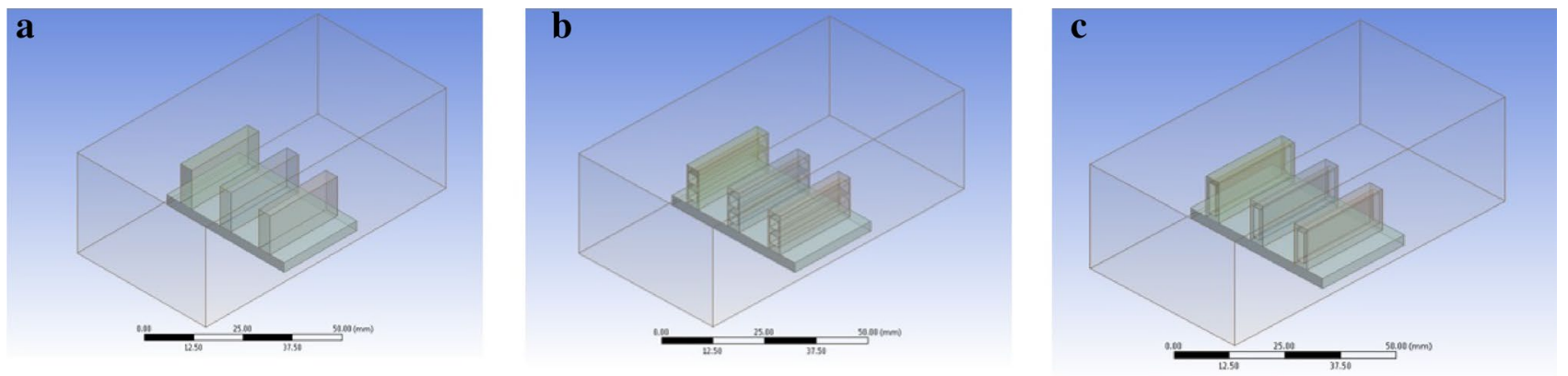

Fig. 3 Computational domain for a plain rectangular fin (a), for a rectangular fin with two square holes (b), for a rectangular fin with one rectangular hole (c) 
Fig. 4 A General view of the meshing
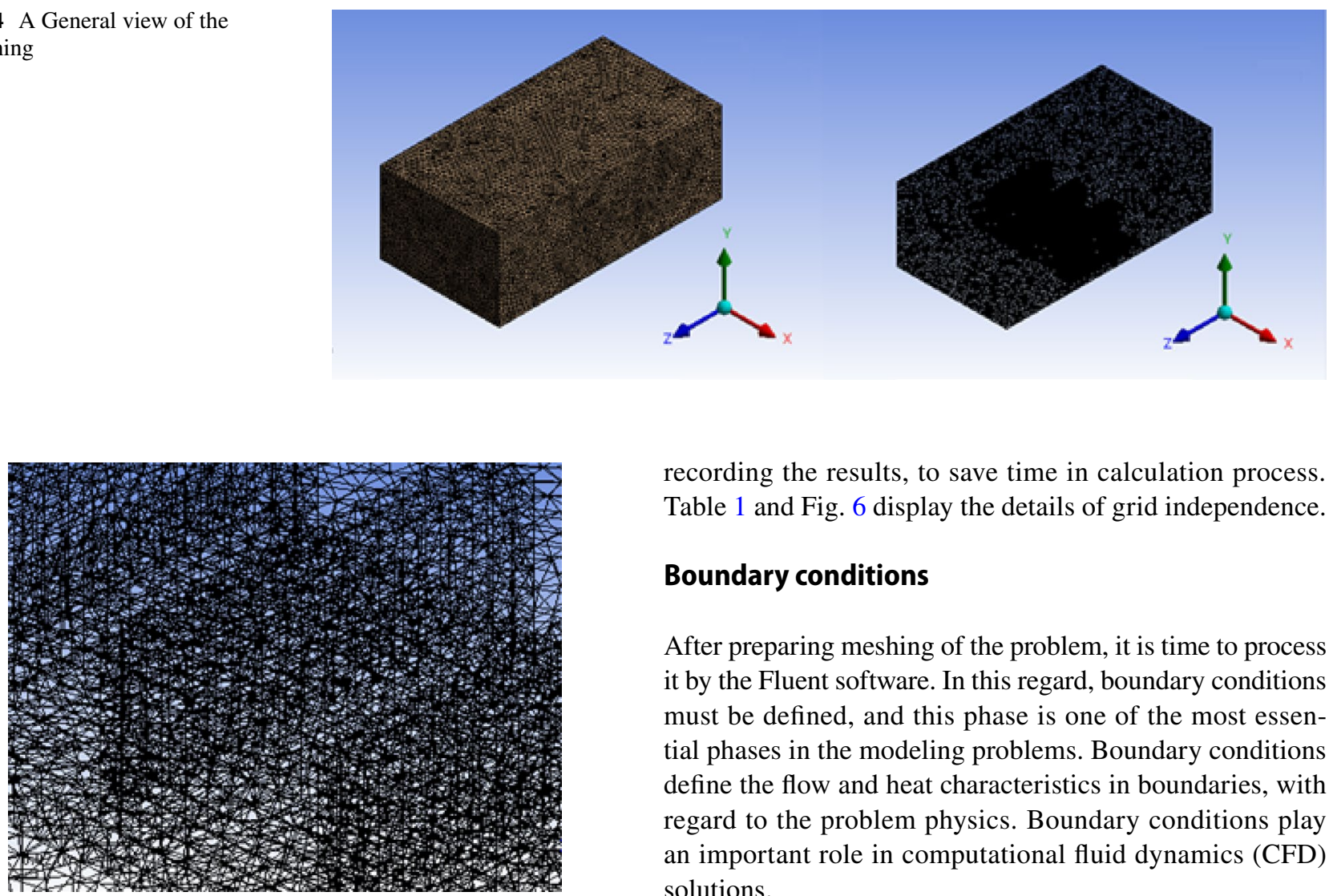

Fig. 5 A close view of the meshing

\section{Grid independence}

In this study, five different meshing for analysis of the grid, independence were made in meshing section of the ANSYS, and all the results were compared with each other. The number of meshing were, respectively, 30,651, 77,345, 90,143, 105,741, and 167,947. To calculate the average Nusselt number in Reynolds, 50,000 was used for plain fin. While comparing the obtained results with other meshing, a very slight difference between the results of smallest meshing and the results of meshing with 105,741 cells was witnessed. As a result, the meshing with 105,741 cells was used for

Table 1 Analysis of grid independence for calculation of Nusselt number in Reynolds 50,000

\begin{tabular}{lc}
\hline Number of mesh & $\begin{array}{l}\text { Average } \\
\text { Nusselt } \\
\text { number }\end{array}$ \\
\hline 30,651 & 57.91 \\
77,345 & 79.02 \\
90,143 & 97.12 \\
105,741 & 110.78 \\
167,947 & 111.23 \\
\hline
\end{tabular}

recording the results, to save time in calculation process. Table 1 and Fig. 6 display the details of grid independence.

\section{Boundary conditions}

After preparing meshing of the problem, it is time to process it by the Fluent software. In this regard, boundary conditions must be defined, and this phase is one of the most essential phases in the modeling problems. Boundary conditions define the flow and heat characteristics in boundaries, with regard to the problem physics. Boundary conditions play an important role in computational fluid dynamics (CFD) solutions.

The boundary conditions are categorized as follows:

- Output and input flow to the border: input pressure, output pressure, velocity input, velocity output, input mass flow, output mass flow, free entrance (ventilation), free output (ventilation), blower or fan, far-reaching pressure field, and blower output.

- Pair and repeating boundaries and wall: wall, axisymmetric boundary, symmetric boundary, periodic boundary

- Internal areas and cells: fluid, solid

- Boundaries of internal plates: blower, radiator, wall, internal area.

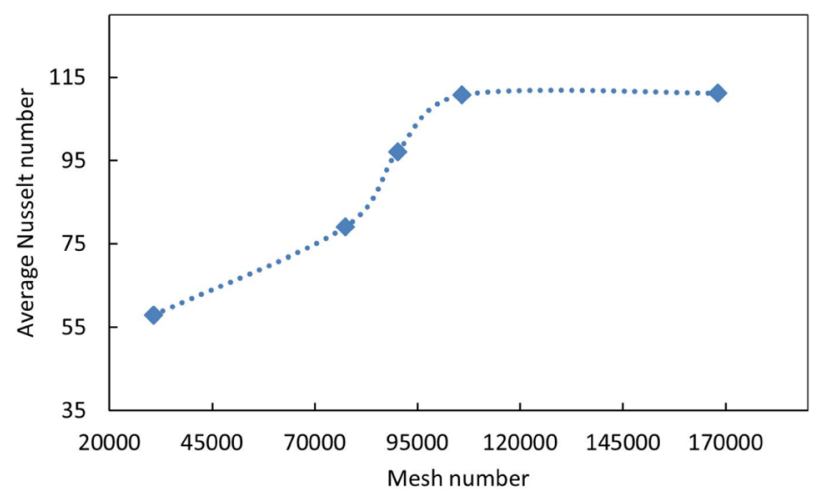

Fig. 6 Analysis of grid independence for calculation of Nusselt number in Reynolds 50,000 
In this research, the entrance side is considered as the boundary condition for velocity input; and the exit side was considered as the boundary condition for output pressure. The wall with no-slip condition was considered for other sides. The flow was considered as 3D, steady and incompressible. The fluid flow occurs parallel with the fins, and free air temperature is $25^{\circ} \mathrm{C}$. The temperature for the surface below the fins was considered to be steady and equal to be $70{ }^{\circ} \mathrm{C}$.

\section{Governing equations}

Incompressible and steady flow equations in turbulence conditions can be defined as below. The following equations are, respectively, continuity, momentum, and energy equations.

$\bar{u}_{i, j}=0$

$\rho\left(\bar{u}_{j} \bar{u}_{i, j}\right)=-\bar{p}_{i}+\left|\mu\left(\bar{u}_{i, j}+\bar{u}_{j, i}\right)-\overline{\rho u_{i}^{\prime} u_{j}^{\prime}}\right|_{, j}$

$\rho C_{p}\left(\bar{u}_{j} \bar{T}_{j}\right)=\left(k \bar{T}_{j}-\overline{\rho C_{p} u_{j}^{\prime} T^{\prime}}\right)_{, j}$

Equation below is used for calculation of heat transfer coefficient:

$h=\frac{-k \frac{\partial T}{\partial n}}{T_{s}-T_{\infty}}$

In above equation, $h$ is the heat transfer coefficient. Another parameter defined in this regard is the dimensionless Nusselt number, which is defined as below:

$N u=\frac{h l}{k}$

If we put the average heat transfer coefficient in this equation, average Nusselt number will be achieved.

\section{Modeling turbulent flows}

With regard to the increasing need of the engineers to have required parameters of fluid flow, finding an applied solution for solving turbulent flow problems is necessary. It is not possible to solve time-dependent Navier-Stokes equations when there are high Reynolds numbers or complex geometries. However, there are two methods for solving Navier-Stokes equations when the fluctuations of turbulent flows are not directly involved in the equations:

1. Reynolds Average Navier-Stokes (RANS)

2. Large Eddy Simulation (LES)

In both above-mentioned methods, additional and new variables are added to the governing equations, and it is needed to obtain them by use of the existing methods and models.

RANS utilizes all the volatility measurements in transitional quantities as average. As a result, this method notably decreases the required calculations, and is appropriate for a wide range of engineering problems.

\section{RANS}

The fluid motion is mathematically described by three equations of mass conservation, momentum, and energy. Under the assumption that flow is incompressible, and there is a linear correlation between gradient of velocity and stress (Newtonian fluid), fluid motion can be expressed by Navier-Stokes equations in a tensor form, as below:

$$
\begin{aligned}
& \underbrace{\frac{\partial\left(\rho u_{i}\right)}{\partial t}}_{\text {Acceleration }}=-\underbrace{\frac{\partial\left(\rho u_{i} u_{j}\right)}{\partial x_{j}}}_{\text {Displacement }}-\underbrace{\frac{\partial P}{\partial x_{i}}}_{\text {Pressure gradient }} \\
& +\frac{\partial}{\partial x_{j}} \underbrace{\left[\mu\left(\frac{\partial u_{i}}{\partial x_{j}}+\frac{\partial u_{j}}{\partial x_{i}}\right)\right]}_{\text {Viscosity effects }}+\underbrace{F_{i}}_{\text {External forces }}
\end{aligned}
$$

$\frac{\partial u_{i}}{\partial t}=0$

On the above equations, $\rho$ denotes air density, $U$ denotes fluid velocity, $P$ denotes static pressure, $\mu$ denotes viscosity, and $F$ denotes external forces imposed to the object. The above-mentioned equations are valid as long as the flow is laminar and without any turbulence. However, when turbulence occurs in flow entrance and vortices grow, transient region (and turbulence afterward) is formed in the flow, and Reynolds number exceeds the critical value. Under this condition, utilizing Navier-Stokes equations is not permissible, and there is a need for an equation that is able to model turbulence. The solution suggested for this problem is changing the whole time-dependent variables into time-averaged components and fluctuating component. For example, instantaneous velocity can be defined as below:

$u_{i}=\overline{u_{i}}+u_{i}^{\prime}$

In the above equation, $\overline{u_{i}}$ denotes velocity average time, and $u_{i}^{\prime}$ is its fluctuating component. The $\overline{u_{i}}$ value can be easily calculated by the equation below:

$\overline{u_{i}}=\frac{1}{\Delta t} \int_{t_{0}}^{t_{0}+\Delta t} u_{i} \mathrm{~d} t$

After replacing the velocity and pressure variables, and time integrating of equations, the average flow equation is obtained. Due to the fact that integration of linear terms of the equations in fluctuating component in momentum and 
conservation equations equals to zero, the only change that is made in these equations due to turbulence will be for the displacement term of the momentum equation (in which multiplication of velocity to its derivatives brings about a non-linear answer). With regard to displacement term, replacement of fluctuating component and average velocity, we will have:

$$
\begin{aligned}
\overline{u_{j} u_{i}}= & \overline{\left(\overline{u_{j}}+u_{j}^{\prime}\right)\left(\overline{u_{i}}+u_{i}^{\prime}\right)}=\overline{\left(\overline{u_{j} u_{i}}\right)}+\overline{\left(\overline{\left.u_{j} u_{i}^{\prime}\right)}\right.} \\
& +\overline{\left(u_{j}^{\prime} \overline{u_{i}}\right)}+\overline{\left(\overline{\left.u_{j}^{\prime} u_{i}^{\prime}\right)}\right.}=\overline{\left(\overline{u_{j} u_{i}}\right)}+\overline{\left(u_{j}^{\prime} u_{i}^{\prime}\right)}
\end{aligned}
$$

Achieved equation after the above-mentioned calculations will be RANS that is as below:

$\frac{\partial\left(\rho \bar{u}_{i}\right)}{\partial t}=-\frac{\partial\left(\rho \bar{u}_{j} \bar{u}_{i}\right)}{\partial x_{j}}-\frac{\partial \bar{P}}{\partial x_{i}}+\frac{\partial}{\partial x_{j}}\left[\left(\mu\left(\frac{\partial \bar{u}_{i}}{\partial x_{j}}+\frac{\partial \bar{u}_{j}}{\partial x_{i}}\right)\right)-\rho \overline{u_{j}^{\prime} u_{i}^{\prime}}\right]+F_{i}$

The RANS equation that models turbulence in system has one further term than the Navier-Stokes equations that is called Reynolds Stress Tensor. In fact, the added term to Navier-Stokes equation is due to separation of the field into two parts of laminar and turbulent. However, as defining the value of this component is impossible by means of analytical calculations, a model must be found by which writing Reynolds stresses based on average quantities would be possible.

Boussinesq presented a model entitled as "Eddy Viscosity", in which Reynolds stresses become related to average strains due to eddy viscosity, by the equation below:

$\tau_{i j}=-\rho \overline{u_{i}^{\prime} u_{j}^{\prime}}=\mu_{t}\left(\frac{\partial \overline{u_{i}}}{\partial x_{j}}+\frac{\partial \overline{u_{j}}}{\partial x_{i}}\right)$

Replacing the above-mentioned equation into Eq. 12, the average flow equation will be as follows:

$\frac{\partial\left(\rho \overline{u_{i}}\right)}{\partial t}=-\frac{\partial\left(\rho \bar{u}_{j} \bar{u}_{i}\right)}{\partial x_{j}}-\frac{\partial \bar{P}}{\partial x_{i}}+\frac{\partial}{\partial x_{j}}\left[\mu_{\mathrm{eff}}\left(\frac{\partial \overline{u_{i}}}{\partial x_{j}}+\frac{\partial \bar{u}_{j}}{\partial x_{i}}\right)\right]+F_{i}$

On which:

$\mu_{\text {eff }}=\mu+\mu_{t}$

Analyzing this equation, it can be concluded that the value of $\mu_{t}$ increased due to consideration of turbulence over viscosity value [28]. Now, if can obtain the value of turbulence viscosity (or eddy viscosity) by use of the correlations among variables, the phases of mathematical modeling of fluid motion will be complete. There are different methods for calculation of eddy viscosity in Fluent software, including single-equation models like Spalart-Allmaras model, two-equation models like $k-\omega$ and $k-\varepsilon$, and seven-equation models like Reynolds stress. In the following, $k-\varepsilon$ model (that are used in the simulation process of the present research) will be explained.

\section{Standard $k-\varepsilon$ model}

Standard $k-\varepsilon$ model was proposed by Launder-Spalding [29]. This model has relatively good accuracy for analysis of Reynolds stress due to turbulent flow. The model is defined by two quantities of Turbulent Kinetic Energy $(K)$ and Dissipation Rate of Turbulent Kinetic Energy $(\varepsilon)$. Knowing the values of $K$ and $\varepsilon$, eddy viscosity is obtained through the formula below:

$\mu_{t}=\rho C_{\mu} k^{2} / \varepsilon$

The Standard $k-\varepsilon$ model equations are:

Kinetic energy of turbulence (K)

$\rho \frac{\partial k}{\partial t}+\rho \bar{u}_{j} \frac{\partial k}{\partial x_{j}}=\tau_{i j} \frac{\partial \bar{u}_{i}}{\partial x_{j}}-\rho \varepsilon+\frac{\partial}{\partial x_{j}}\left[\left(\mu+\mu_{t} / \sigma_{k}\right) \frac{\partial k}{\partial x_{j}}\right]$

Dissipation Rate of Turbulent Kinetic Energy $(\varepsilon)$

$\rho \frac{\partial \varepsilon}{\partial t}+\rho \overline{u_{j}} \frac{\partial \varepsilon}{\partial x_{j}}=C_{\varepsilon 1} \frac{\varepsilon}{k} \tau_{i j} \frac{\partial \overline{u_{i}}}{\partial x_{j}}-C_{\varepsilon 2} \rho \frac{\varepsilon^{2}}{k}+\frac{\partial}{\partial x_{i}}\left[\left(\mu+\mu_{t} / \sigma_{\varepsilon}\right) \frac{\partial \varepsilon}{\partial x_{j}}\right]$

In the above equation, $\tau_{i j}$ is the Reynolds stress tensor, and it equals with:

$\underbrace{\tau_{i j}}=\underbrace{2 \mu_{t} S_{i j}}-\underbrace{2 / 3 \rho k \delta_{i j}}$

On Eq. (18), $\delta$ denotes Kronecker Delta, $k$ denotes mean turbulent kinematic energy, and $S$ denotes strain rate tensor. The following equations are defined for the above-mentioned parameters:

$\delta_{i j}=1(i=j=1)$

$k=\frac{1}{2} \overline{u_{i}^{\prime} u_{i}^{\prime}}$

$S_{i j}=\frac{1}{2}\left(\frac{\partial \overline{u_{i}}}{\partial x_{j}}+\frac{\partial \overline{u_{j}}}{\partial x_{i}}\right)$

Moreover, the constant values of $\sigma_{k}, \sigma_{\varepsilon}, C_{\varepsilon 1}, C_{\varepsilon 2}$ and $C_{\mu}$ that are usually obtained from wind tunnel test are displayed on Table 2.

As observed, Reynolds stress tensor in standard $k$ - $\varepsilon$ model has an additional term (third sentence) than the Boussinesq equation. Adding this term to Reynolds stress equation is due to consideration of vertical Reynolds stresses in $k-\varepsilon$ model. It

Table 2 Constant values for eddy viscosity equations, $K$, and $\varepsilon$

\begin{tabular}{llllll}
\hline Model & $C_{\mu}$ & $C_{\varepsilon 1}$ & $C_{\varepsilon 2}$ & $\sigma_{k}$ & $\sigma_{\varepsilon}$ \\
\hline Standard $k-\varepsilon$ & 0.09 & 1.44 & 1.92 & 1 & 1.3 \\
\hline
\end{tabular}


is needed to be mentioned that $k$ - $\varepsilon$ model is only valid for quite turbulent flow, and is not able to predict the transitional phase of the flow around the wall. $k-\varepsilon$ RNG model is used for solving the problem in the present study.

\section{Numerical analysis}

Within the model under analysis, a triangle grid was considered for rectangular cube area and the fins too. Standard method was used for pressure discretization, and the Firstorder upwind method was used for momentum and turbulence discretization. Moreover, second-order upwind method was used for energy discretization. By use of this method, the results obtained have higher accuracy. As the model is a steady model, and regular grids are used, simple algorithm is used for the pressure-velocity coupling pattern. In this article, the convergence measure for reduction of remainder for such variables as momentum and mass was considered lower than $10^{-3}$, and for energy was considered $10^{-6}$. As mentioned before, $k-\varepsilon$ RNG turbulence model was used in this study, as this model is more accurate than others.

\section{Validation}

Due to lack of experimental results regarding plain perforated fins in turbulent flow, the plain fin in turbulent flow model was used to compare the results of this study with the results achieved in the experimental study of El-Sayed et al. [30]. In this regard, fluctuations of average Nusselt number relative to Reynolds number were compared in both studies. In the experimental study of El-Sayed et al. [30], an array of rectangular parallel fins were placed in different direction, and the results were compared with each other. The best result was achieved under the parallel flow condition. El-Sayed et al. [30] studied the geometric effects of an array of fins as well as the heat transfer

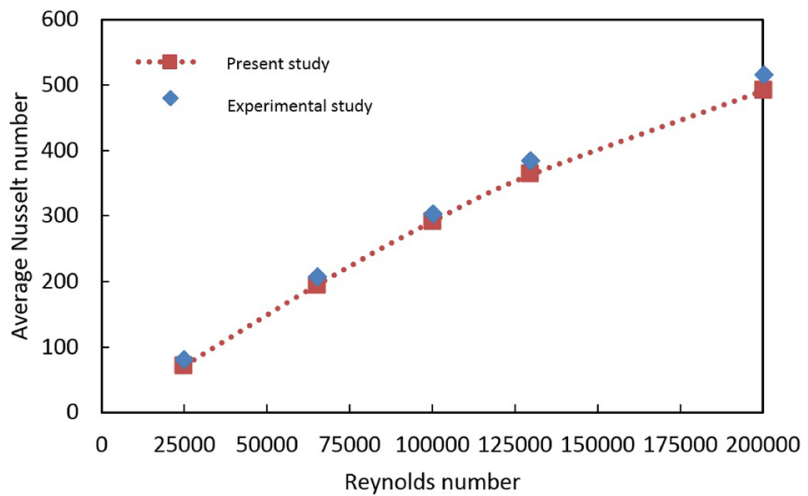

Fig. 7 Comparing fluctuations of average Nusselt number relative to Reynolds number in the present study and the study of El-Sayed et al. [30] characteristics. As depicted in Fig. 7, there is an acceptable conformity between the results of the present study and the study of El-Sayed et al. [30].

\section{Results}

The results of the numerical method and convergence are discussed in this section. For validation of the results, they were compared with the results of El-Sayed et al. [30]. Afterward, the results of numerical analysis of a plate fin exchanger with different geometries with Fluent software are represented. The working fluid was considered to be air, and fins' material was considered to be aluminum in this study. The flow developed and flow conditions were considered steady. Moreover, the fluid flow parallel to fins passed on the surface. The fluid flow was turbulent, and Reynolds number was between 20,000 and 50,000. The input air temperature was $300 \mathrm{~K}$, and the fins were placed on a plate with constant heat flux of $1200 \mathrm{w} / \mathrm{m}^{2}$.

\section{Fluctuations of average heat transfer coefficients in the fins}

Figure 8 displays fluctuations of average heat transfer coefficients in the plain fins, fins with one hole and two holes, according to Reynolds number. As observed, the fin with two holes has a higher heat transfer rate than others. Making a hole in rectangular fin, the heat transfer surface increases notably, and heat transfer increases accordingly, in a way that in Reynolds number 50,000, heat transfer coefficient for the fin with two holes was about $7 \%$ higher than the plain fin, and the heat transfer coefficient for the fin with one hole was about $6 \%$ higher than the plain fin. Also, it can be concluded that by increase of Reynolds number, the heat transfer coefficient increased in all fins.

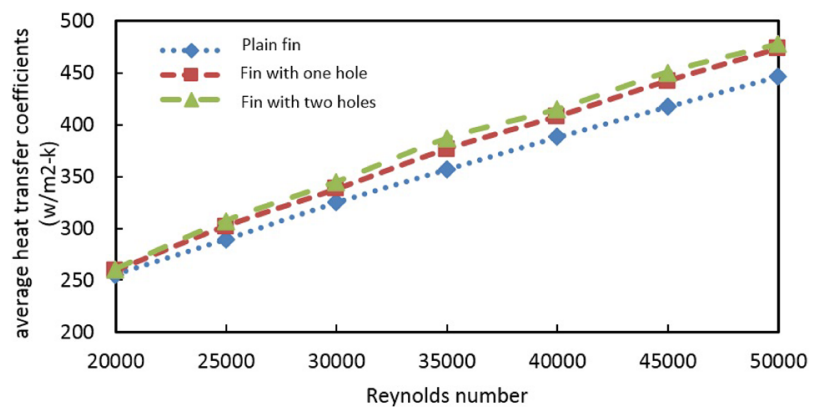

Fig. 8 Fluctuations of average heat transfer coefficients in the fins 


\section{Fluctuations of average Nusselt number in fins}

Figure 9 displays the fluctuations of average Nusselt number for plain fins, fins with one hole and two holes relative to Reynolds number. As observed, the value of average Nusselt number increases with a high slope, as the Reynolds number increases. The highest amount of increase is seen at Reynolds number 50,000. With the increase of Reynolds number up to 50,000 , average Nusselt number increased as much as $84 \%$ compared to Reynolds number 20,000 for the fin with two holes. With the increase of Reynolds number from 20,000 to 50,000 , average Nusselt number increased $82 \%$ for the fin with one hole, and $75 \%$ for the plain fin. Important point here is that higher average of Nusselt number for the fin with two holes (than the other two fins) is due to passage of the flow from the fins and increase of heat transfer.

\section{Fluctuations of pressure drag force in the fins}

Figure 10 displays the fluctuations of pressure drag force relative to Reynolds number in the plain fin, the fin with one hole, and the fin with two holes. It is obvious that plain

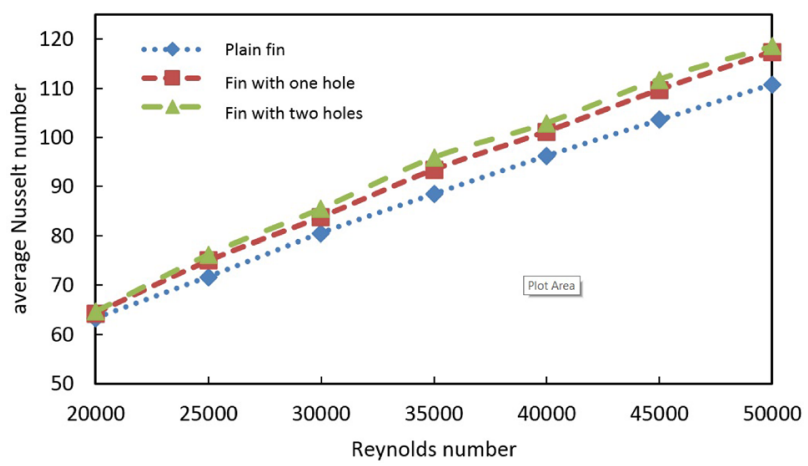

Fig. 9 Fluctuations of average Nusselt number according to Reynolds number in the fins

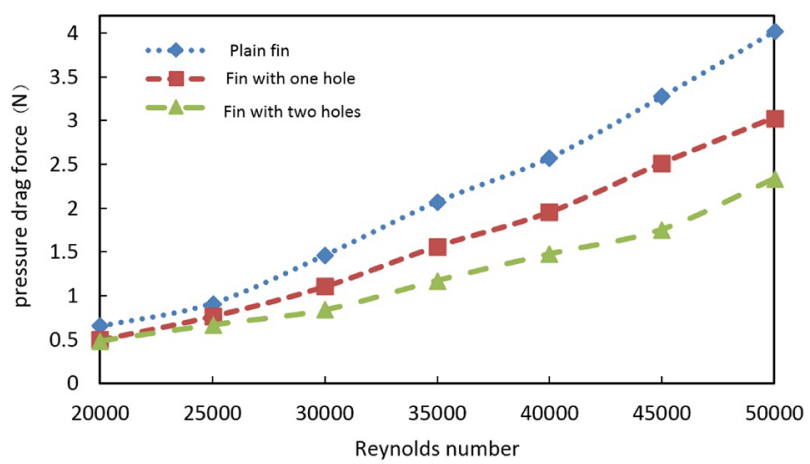

Fig. 10 Fluctuations of pressure drag force according to Reynolds number in the fins fin had a higher pressure drag force than the other fins, and the fin with one hole had a higher pressure drag force than the fin with two holes. Moreover, the pressure drag force increased with the increase of Reynolds number, and the increase slope is more intensive for the plain fin than the other two fins. Decrease of pressure drag force in the perforated fins is due to passage of a part of the flow from the hole. With the passage of the flow from the holes, a part of the created weak behind the fins is lost, and as the rotational flow decreases behind the fins, pressure difference decreases; and accordingly, pressure drag force decreases.

\section{Fluctuations of viscous drag force in the fins}

Figure 11 displays fluctuations of viscous drag force relative to Reynolds number in the plain fins, the fin with one hole, and the fin with two holes. It is clear that the perforated fins had a higher viscous drag force than the plain fin, and the fin with one hole had a higher viscous drag force than the fin with two holes. The imposed force to perforated fins was higher than the imposed force to the plain fin. Increase of viscous drag is due to increase of the fin contact surface in the holes. In fact, by passage of the flow from the holes, a higher surface of the fluid is touched by the fins. Moreover, the viscous drag force increased as the Reynolds number boosted. The highest amount of viscous drag force is observed at Reynolds number 50,000.

\section{Fluctuations of total drag force imposed to fins}

Figure 12 depicts fluctuations of total drag force imposed to the three fins (that is obtained by summing up pressure drag force and viscous drag force). Analysis of the figure reveals that total drag force imposed to the plain fin is higher than the total drag force imposed to perorated fins, and the reason is increase of the imposed pressure on the fin contact surface due to the strike of the flow to the fin. However, with passage of the flow form the holes in perforated fins, the

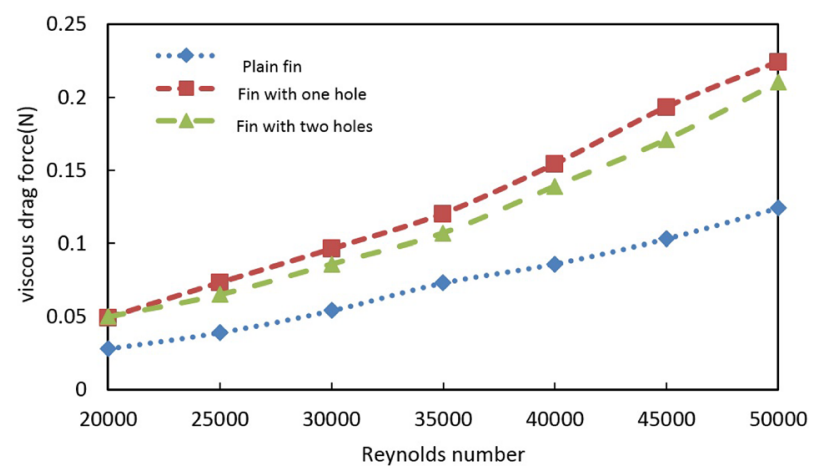

Fig. 11 Fluctuations of viscous drag force in the fins according to Reynolds number 


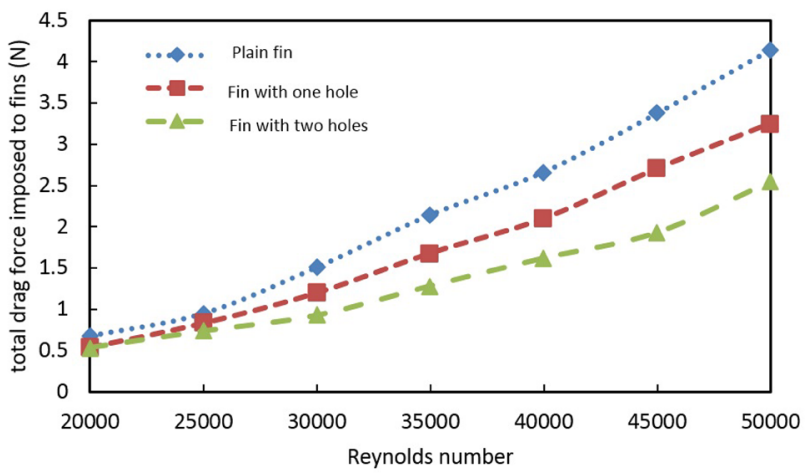

Fig. 12 Fluctuations of total drag force imposed to fins according to Reynolds number

pressure decreases notably. Moreover, the total drag force increases with the increase of Reynolds number. The fin with two holes had the lowest amount of total drag force.

\section{Comparison of the highest pressure imposed to the fins}

Table 3 displays the results of comparing the highest pressure imposed to the fins with regard to the Reynolds number. Analysis of the table reveals that with a constant Reynolds number, plain fin had the highest amount of maximum pressure (pascal). By making holes on the plain fins along the flow direction, the amount of pressure decreases due to passage of the flow from the holes. Furthermore, the fins with two square holes had the lowest amount of maximum pressure. Figures 13, 14 and 15 display the distribution of static pressure on the three fins under study at Reynolds number

Table 3 Comparing the highest pressure imposed to the fins based on Reynolds number

\begin{tabular}{lcc}
\hline Fin & $\begin{array}{l}\text { Maximum pressure } \\
\text { (pascal) }\end{array}$ & Reynolds number \\
\hline Plain fin & 2191 & 20,000 \\
& 4907 & 30,000 \\
& 8668 & 40,000 \\
Fin with one hole & 13,503 & 50,000 \\
& 2092 & 20,000 \\
& 4680 & 30,000 \\
& 8263 & 40,000 \\
Fin with two holes & 12,866 & 50000 \\
& 2056 & 20,000 \\
& 4490 & 30,000 \\
& 7942 & 40,000 \\
& 12,581 & 50,000 \\
\hline
\end{tabular}

\section{Comparison of the temperature distribution along the fins}

Figures 16, 17, 18 display the fluctuations of temperature distribution along the plain fin, the fin with one hole, and the fin with two holes based on Reynolds number. As observed in the figures below, temperature increases with the increase of fins' length, and the highest amount is for fin number 2 that is surrounded by the other two fins. Simultaneous analysis of the three cases under analysis revealed that plain fins has higher temperature than the perforated fins.

\section{Conclusion}

The author in this paper conducted a numerical analysis of heat transfer around an array of plain and perforated fins that were placed on a plate with constant thermal flux on the Reynolds range of 20,000-50,000. The flow was assumed to be 3D, steady, incompressible, and turbulent. To solve equations, First-order and second-order discretization method were used; and, SIMPLE algorithm with the help of Fluent software was used for obtaining pressure-velocity coupling pattern. The results of the study revealed that $k$ - $\varepsilon$ RNG turbulence model is an appropriate model for solving the problem of flow around the fins, and analysis of the fins' thermal characteristics. The results of the study confirmed that changing plain fins into perforated fins brings about an increase of convection heat transfer coefficient and Nusselt number-in a way that fins with two square holes had the highest amount of convection heat transfer coefficient and Nusselt number. Increase of Reynolds number leads in an outstanding increase of heat transfer coefficient and Nusselt number in a way that mentioned parameters in the fins with two square holes increased $84 \%$. The point to be careful is that the total drag force imposed to the plain fins is higher than the total drag force imposed to perforated fins. By making holes on the plain fins and passage of the flow from the holes, the pressure marvelously decreases; and, the total drag force imposed to the fins decreases accordingly. Moreover, the total drag force imposed to the fins increases as the Reynolds number increases; as a result, the fins with two holes have the lowest imposed total drag force. Comparing the temperature distribution along the fins made it clear that increase of the fin length leads in increase of the temperature, and the highest temperature belonged to the middle fin that was surrounded by the fins beside it. The essential point to mention is that most of the previously conducted research with the aim of increasing heat transfer

20,000 . 


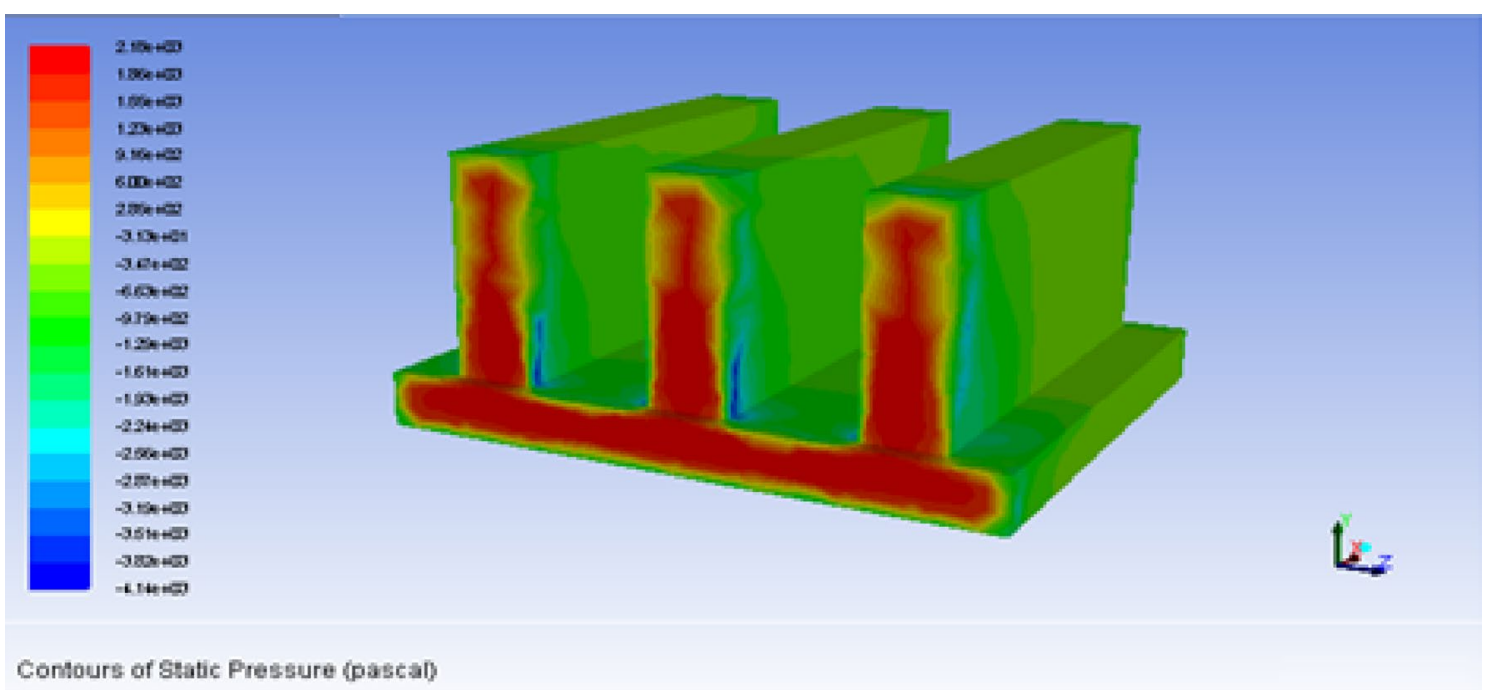

Fig. 13 Distribution of static pressure on plain fin on Reynolds number 20,000

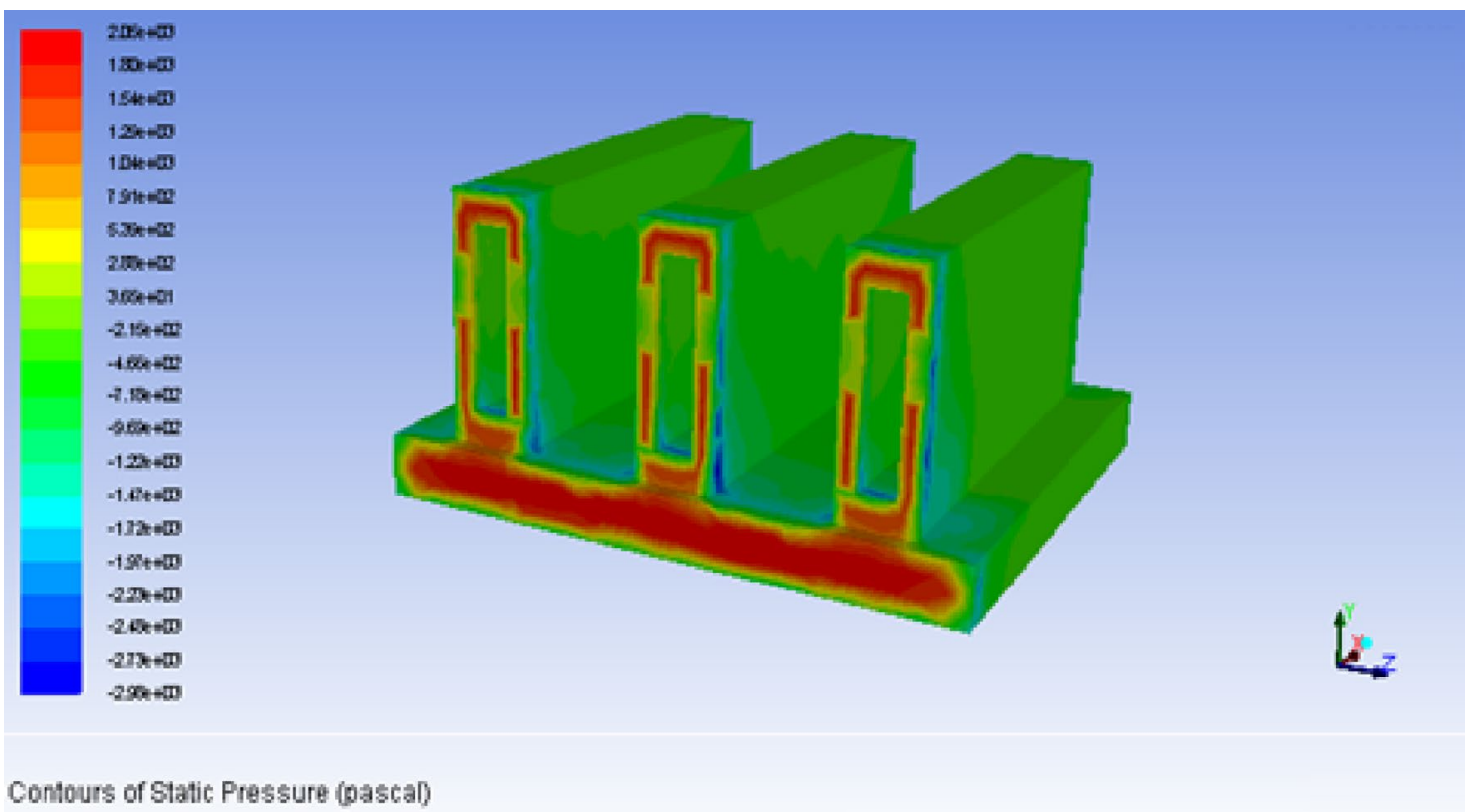

Fig. 14 Distribution of static pressure on the fin with one rectangular hole on Reynolds number 20,000

led to an increase of pressure drop. It was concluded in this study that by making some holes along the passing flow on the plain fins, pressure drop decreases, while heat transfer improves outstandingly. Therefore, doing will also decrease the weight and the cost of the fins. 


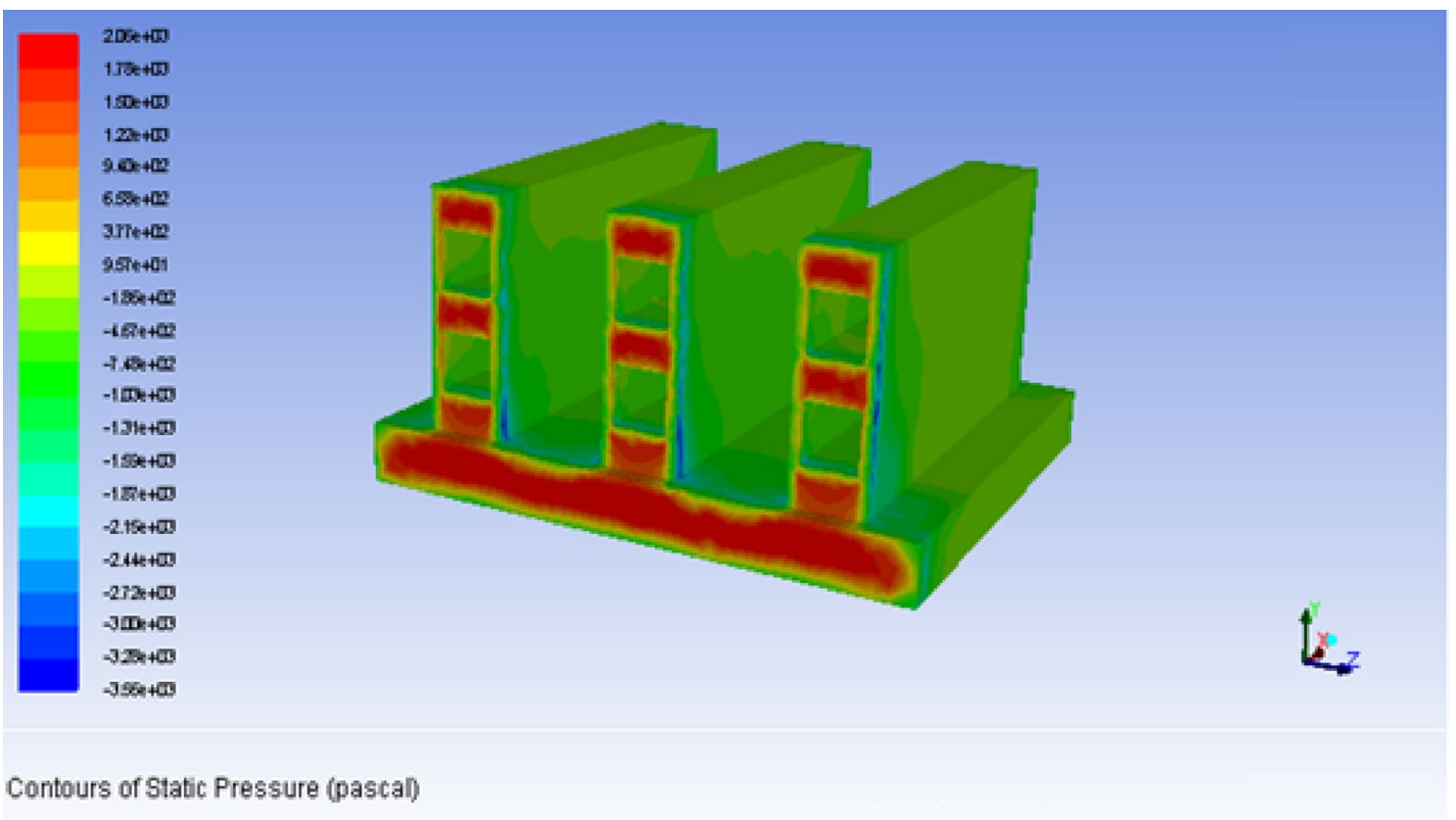

Fig. 15 Distribution of static pressure on the fin with two square hole on Reynolds number 20,000

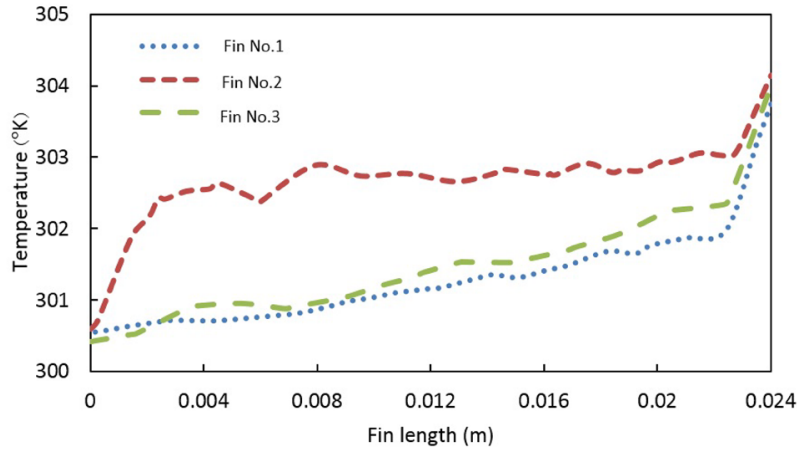

Fig. 16 Temperature distribution along plain fin in Reynolds number 30,000

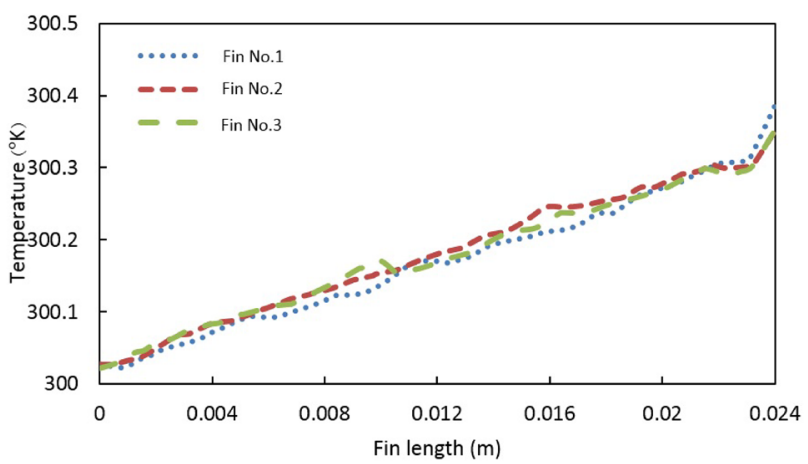

Fig. 17 Temperature distribution along the fin with a rectangular hole in Reynolds number 30,000

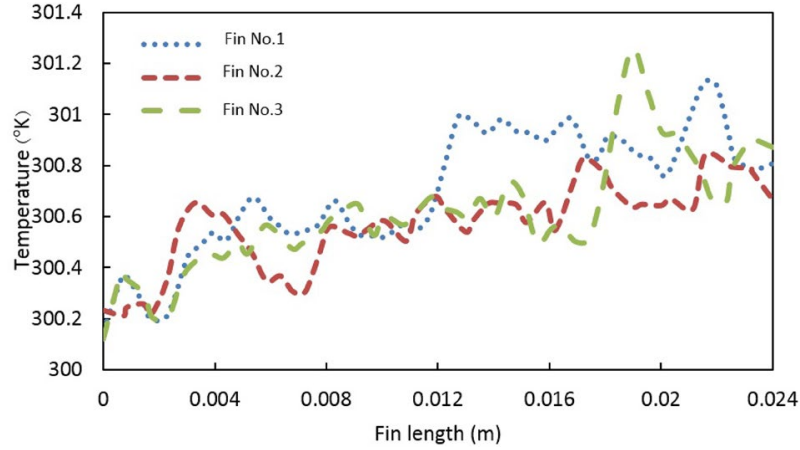

Fig. 18 Temperature distribution along the fin with two square holes in Reynolds number 30,000

\section{Compliance with ethical standards}

Conflict of interest The authors declare no conflict of interests.

Open Access This article is distributed under the terms of the Creative Commons Attribution 4.0 International License (http://creativeco mmons.org/licenses/by/4.0/), which permits unrestricted use, distribution, and reproduction in any medium, provided you give appropriate credit to the original author(s) and the source, provide a link to the Creative Commons license, and indicate if changes were made. 


\section{References}

1. Zohuri, B.: Nuclear Energy for Hydrogen Generation Through Intermediate Heat Exchangers: A Renewable Source of Energy. Springer, New York (2016)

2. Sahu, A.K., Sahu, N.K., Sahu, A.K.: Benchmarking CNC machine tool using hybrid-fuzzy methodology: a multi-indices decision making (MCDM) approach. Int. J. Fuzzy Syst. Appl. (IJFSA) 4, 28-46 (2015)

3. Tahseen, T.A., Ishak, M., Rahman, M.M.: Performance predictions of laminar heat transfer and Pressure drop in an in-line flat tube bundle using an adaptive neuro-fuzzy inference system (ANFIS) model. Int. Commun. Heat Mass Transfer 50, 85-97 (2014)

4. Sinha, A., Chattopadhyay, H., Iyengar, A.K., Biswas, G.: Enhancement of heat transfer in a fin-tube heat exchanger using rectangular winglet type vortex generators. Int. J. Heat Mass Transfer 101, 667-681 (2016)

5. Jonsson, H., Moshfegh, B.: Modeling of the thermal and hydraulic performance of plate fin, strip fin, and pin fin heat sinksinfluence of flow bypass. IEEE Trans. Compon. Packag. Technol. 24, 142-149 (2001)

6. Kays, W.M., London, A.L.: Compact Heat Exchangers. McGraw-Hill, New York (1984)

7. Velayati, E., Yaghoubi, M.: Numerical study of convective heat transfer from an array of parallel bluff plates. Int. J. Heat Fluid Flow 26, 80-91 (2005)

8. Razelos, P., Kakatsios, X.: Optimum dimensions of convectingradiating fins: part I-longitudinal fins. Appl. Therm. Eng. 20, 1161-1192 (2000)

9. Wang, Y.Q., Dong, Q.W., Liu, M.S., Wang, D.: Numerical study on plate-fin heat exchangers with plain fins and serrated fins at low reynolds number. Chem. Eng. Technol. 32, 1219-1226 (2009)

10. Asako, Y., Faghri, M.: Parametric study of turbulent three-dimensional heat transfer of arrays of heated blocks encountered in electronic equipment. Int. J. Heat Mass Transfer 37, 469-478 (1994)

11. Kitto, J., Robertson, J.: Effects of maldistribution of flow on heat transfer equipment performance. Heat Transfer Eng. 10, 18-25 (1989)

12. Ranganayakulu, C., Seetharamu, K.: The combined effects of longitudinal heat conduction, flow nonuniformity and temperature nonuniformity in crossflow plate-fin heat exchangers. Int. Commun. Heat Mass Transfer 26, 669-678 (1999)

13. Ranganayakulu, C., Seetharamu, K.: The combined effects of wall longitudinal heat conduction, inlet fluid flow nonuniformity and temperature nonuniformity in compact tube-fin heat exchangers: a finite element method. Int. J. Heat Mass Transfer 42, 263-273 (1999)

14. Mueller, A.: Effects of some types of maldistribution on the performance of heat exchangers. Heat Transfer Eng. 8, 75-86 (1987)

15. Shah, R., London, A.: Effects of nonuniform passages on compact heat exchanger performance. J. Eng. Power 102, 653-659 (1980)

16. Khan, T.A., Li, W.: Optimal design of plate-fin heat exchanger by combining multi-objective algorithms. Int. J. Heat Mass Transfer 108, 1560-1572 (2017)
17. Cho, D.H., Seo, S.K., Lee, C.J., Lim, Y.: Optimization of layer patterning on a plate fin heat exchanger considering abnormal operating conditions. Appl. Therm. Eng. 127, 1036-1048 (2017)

18. Mueller, A., Chiou, J.: Review of various types of flow maldistribution in heat exchangers. Heat Transfer Eng. 9, 36-50 (1988)

19. Wais, P.: Influence of fin thickness and winglet orientation on mass and thermal efficiency of cross-flow heat exchanger. Appl. Therm. Eng. 102, 184-195 (2016)

20. Han, H., He, Y.L., Li, Y.S., Wang, Y., Wu, M.: A numerical study on compact enhanced fin-and-tube heat exchangers with oval and circular tube configurations. Int. J. Heat Mass Transfer 65 , 686-695 (2013)

21. Čarija, Z., Franković, B., Perčić, M., Čavrak, M.: Heat transfer analysis of fin-and-tube heat exchangers with flat and louvered fin geometries. Int. J. Refrig 45, 160-167 (2014)

22. Yeom, T., Simon, T., Zhang, T., Zhang, M., North, M., Cui, T.: Enhanced heat transfer of heat sink channels with micro pin fin roughened walls. Int. J. Heat Mass Transfer 92, 617-627 (2016)

23. Wang, G.L., Yang, D.W., Wang, Y., Niu, D., Zhao, X.L., Ding, G.F.: Heat transfer and friction characteristics of the microfluidic heat sink with variously-shaped ribs for chip cooling. Sensors. 15, 9547-9562 (2015)

24. Salehi, S.: Simulation of Air-to-Air Plate Heat Exchangers for Analyzing the Possibility of Baffle Installation, Analyzing the Effects of Input Duct Shape and Geometry of Used Fins on the Heat Exchanger Performance, Master's thesis, Sharif Industrial University, Tehran, Iran (2012)

25. Das, P., Ghosh, I.: Thermal design of multistream plate fin heat exchangers-a state-of-the-art review. Heat Transfer Eng. 33, 284 $300(2012)$

26. Mohammad Zamani, G.: Modeling and Controlling Plate Heat Exchanger, Master's thesis, Sharif Industrial University, Tehran, Iran (1994)

27. Butterworth D.: Design and application of twisted tube exchangers. In: European Research Meeting on the Future Needs and Developments in Heat Exchanger Technology-Advances in Industrial Heat Transfer, IChemE, pp. 87-95 (1996)

28. Chen, Y.S., Kim, S.W.: Computation of Turbulent Flows Using an Extended k- $\varepsilon$ Turbulence Closure Model, Report No. NASA CR-179204, Universities Space Research Association, Washington, D.C., USA (1987)

29. Launder, B., Spalding, D.: The numerical computation of turbulent flows. Comput. Methods Appl. Mech. Eng. 3, 269-289 (1974)

30. El-Sayed, S.A., Mohamed, S.M., Abdel-latif, A.M., Abdel-hamid, E.A.: Investigation of turbulent heat transfer and fluid flow in longitudinal rectangular-fin arrays of different geometries and shrouded fin array. Exp. Therm. Fluid Sci. 26, 879-900 (2002)

Publisher's Note Springer Nature remains neutral with regard to urisdictional claims in published maps and institutional affiliations. 